\title{
Retrograde Axonal Transport in Rat Sciatic Nerve After Nerve Crush Injury
}

\author{
DAVID J. FINK, ${ }^{1}$ DAVID PURKISS AND MARINA MATA \\ Neurology Research Laboratory \\ University of Michigan and VA Medical Center, Ann Arbor, MI
}

Received 16 February 1987

\begin{abstract}
FINK, D. J., D. PURKISS AND M. MATA. Retrograde axonal transport in rat sciatic nerve after nerve crush injury. BRAIN RES BULL 19(1) 29-33, 1987.- We investigated the quantitative alterations in retrograde transport of proteins folluwing a nerve crush injury using the ${ }^{3} \mathrm{H} \mathrm{N}$-succinimidyl propionate $\left({ }^{3} \mathrm{H} \mathrm{NSP}\right)$ method in rat sciatic nerve. After subepineurial injection of ${ }^{3} \mathrm{H}$ NSP into the nerve the amount of radioactively labeled proteins accumulating in the cell bodies of the motor and sensory neurons was determined 1 day or 7 days later in nerves which had been crushed distal to the injection site $1,3,5,7$, or 33 days prior to ${ }^{3} \mathrm{H}$ NSP labeling. One day accumulation in the DRG and spinal cord was not altered by nerve crush. Seven day accumulation in the DRG was initially sightly increased, then fell to $73 \%$ of control by 7 days, remaining reduced 33 days after crush. Seven day accumulation in the spinal cord was reduced to $25 \%$ of control 1 day after crush and remained at that low level except for 5 days post-crush when a normal amount of labeled protein was transported to the spinal cord. The time course of these changes suggests that quantitative alterations in retrograde transport may be involved in the long-term trophic interactions between the cell body and periphery, but are too slow to account for the earliest perikaryal responses to injury. In addition, the difference between the alterations of retrograde transport in motor and sensory neurons may reflect fundamental differences in the composition of retrograde transport in those different systems.
\end{abstract}

Retrograde axonal transport Sciatic nerve Injury ${ }^{3} \mathrm{H}$ NSP Regeneration

THE neuronal reaction to distant axonal injury suggests that biochemical signals, ascending from the axon to the cell body, trigger and to some extent control the perikaryal response to injury [6]. The application of colchicine, which blocks the retrograde transport of macromolecules, can both induce a chromatolytic response in normal neurons [20] or delay the onset of chromatolysis after a nerve injury [22]. However the identity of the signals remains obscure.

Specific alterations in retrograde axonal transport following nerve crush injury have been described in a variety of systems. Exogenous macromolecular tracers are taken up into axons at the site of a nerve crush and transported retrogradely to the cell body $[19,23]$. The retrograde "turnaround" transport of endogenous dopamine beta hydroxylase and of rapidly transported proteins radioactively labeled by amino acid injection are both altered by nerve crush $[3,5,21]$.

We have used the in vivo covalent labeling reagent ${ }^{3} \mathrm{H}$ $\mathrm{N}$-succinimidyl propionate ( ${ }^{3} \mathrm{H} \mathrm{NSP}$ ) to radioactively label axonal proteins in vivo and measured the subsequent accumulation of labeled proteins in the dorsal root ganglion and ventral horn of spinal cord $[7,8]$. We have previously found that in DRG and spinal cord the early appearance of labeled proteins is followed by the subsequent accumulation of larger amounts of the same proteins [8]. We have found more recently that this accumulation is diminished by intoxication with the neurotoxin beta beta' imminodipropionitrile (IDPN) and is also decreased after the induction of diabetes with streptozotocin $[9,10]$. These results suggest that some of the labeled retrogradely transported proteins might be important in normal signaling from the axon to the cell body, and that decreased delivery of those proteins might play a role in controlling the cell body response in those neuropathic conditions.

In order to further elucidate the possible role of these retrogradely transported proteins in transmitting signals of the axonal condition to the neuronal perikaryon, we undertook the current study of retrograde axonal transport following a crush injury to sciatic nerve.

\section{METHOD}

Male Sprague Dawley rats (175-250 grams at the time of nerve crush) were used in all experiments. Under chloral hydrate anesthesia the sciatic nerve was exposed in the gluteal region and crushed 45 seconds using a Jewelers forceps. The wound was closed with wound clips and the completeness of the lesion assessed by paresis of the ipsilateral

${ }^{1}$ Requests for reprints should be addressed to David J. Fink, Neurology (127), 2215 Fuller Road, Ann Arbor, MI 48105. 
foot on awakening. At 1,3,5,7, or 33 days after injury the animal was anesthetized again and the nerve injected with ${ }^{3} \mathrm{H}$ NSP at a point $1-2 \mathrm{~cm}$ proximal to the crush injury.

\section{"H NSP Injertion}

"H NSP (50 Ci/mmol in hexane/ethyl acetate, New England Nuclear) was evaporated to dryness under vacuum and resuspended in 2.5 microliters of physiologic saline, $\mathrm{pH} 7.4$. 1.25 microliters containing 125 microCuries was injected subepineurially over 5 minutes using a 31 gauge needle attached to a Hamilton syringe in a Harvard infusion pump. and the wound closed with wound clips. At 1 day or 7 days after injection the animals were again anesthetized with chloral hydrate and sacrificed by perfusion through the heart with $0.1 \mathrm{M}$ phosphate buffered saline, $\mathrm{pH} 7.4$. The ipsilateral sciatic nerve, bilateral L4, L5 and L6 DRG and the spinal cord were rapidly removed and frozen on dry ice. The total TCA precipitable radioactivity in the nerve, DRG, and the ventral horn of lumbar spinal cord were determined as described previously $[8,9]$.

The amount of retrograde axonal transport to the motor and sensory neuronal cell bodies was calculated by determining the amount of TCA precipitable radinactivity in the DRG and the ventral horn of spinal cord respectively (ipsilateral to injection minus contralateral) at 1 day or at 7 days after ${ }^{3} \mathrm{H}$ NSP injection. These results were expressed as both as total DPM, and as the ratio of DPM in the cell body to DPM remaining in the nerve ("ratio"). For presentation, the values of total DPM or the cell body/nerve ratio in experimental animals were normalized against the total DPM or the cell body/nerve ratio respectively in control animals and these normalized values (with control $=1$ ) are presented in the tables and figures.

\section{Statistical Analysis}

We performed one way analysis of variance on both the cell body DPM and on the cell body to nerve ratios, using Bonferroni's procedure for multiple comparisons (16) to control for the multiple comparisons being made.

\section{Light Microscepic Autoradiography}

Under chloral hydrate anesthesia the animals were perfused through the heart with $75 \mathrm{mM}$ phosphate buffer for 1 minute followed by $3 \%$ glutaraldehyde, $0.5 \%$ paraformaldehyde in $75 \mathrm{mM}$ phosphate buffer for 1 hour. The tissue was fixed for an additional 2 hours, washed overnight in phosphate buffer, postfixed in $2 \% \mathrm{OsO}_{4}$ in the same buffer, dehydrated in ethanol and embedded in Polybed-Araldite. Semithin (1 micron) sections were coated with Kodak NTB-2 nuclear track emulsion, exposed in the dark at $4^{\circ} \mathrm{C}$ and developed in Kodak D-19 developer.

\section{RESULTS}

Transport to the cell bodies of the sensory neurons in the DRG 1 day after "H NSP labeling of axonal proteins was not significantly altered by nerve crush. There was a trend towards an increase at 5 days post-crush but it was not statistically significant, and by 7 days post-crush the amount of transport was the same as for 1 day post-crush (Table 1).

However, the accumulation of transported proteins 7 days after injection was changed by the crush (Fig. 1). At 1 and 3 days post-crush the amount of transport was slightly greater than normal. This amount decreased by 5 days and
TABLE I

ONE DAY TRANSPORT TO DRG AND SPINAL CORD

\begin{tabular}{lcccc}
\hline $\begin{array}{l}\text { Days } \\
\text { Post- } \\
\text { Crush }\end{array}$ & DRG & DRG/N & SC & SC/N \\
\hline & & & & \\
1 & $0.86 \pm 0.07$ & $0.85 \pm 0.07$ & $0.70 \pm 0.20$ & $0.68 \pm 0.16$ \\
3 & $0.99 \pm 0.14$ & $1.03 \pm 0.12$ & $0.77 \pm 0.28$ & $0.87 \pm 0.36$ \\
5 & $1.19 \pm 0.12$ & $1.33 \pm 0.21$ & $0.77 \pm 0.20$ & $0.92 \pm 0.28$ \\
7 & $0.82 \pm 0.14$ & $0.78 \pm 0.09$ & $0.81 \pm 0.19$ & $0.88 \pm 0.28$
\end{tabular}

Accumulation of radioactively labeled proteins in the DRG and spinal cord 1 day after labeling of axonal proteins ${ }^{3} \mathrm{H}$ NSP. Data is presented both as DRG and spinal cord DPM (normalized against control animals) and as the ratio of DRG or spinal cord radioactivity to total radioactivity remaining in the nerve at the time of sacrifice (also normalized against control animals). Mean \pm SEM. $N=5,5.6$. 9,4 for control and $1,3,5.7$ days post-crush respectively. None of the differences are statistically significant.

by 7 days post-crush was $73 \%$ of control, a change which was not statistically significantly different from the control but was significantly reduced from both the 1 day and the 3 day post-crush values $(p<0.01)$. This reduction was still present 33 days after nerve crush $(p<0.01)$, by which time nerve regeneration had occurred.

Transport to the motor neuron cell bodies at 1 day after "H NSP injection, like transport to the sensory neurons, was not changed by nerve crush (Table 1). However 7 day transport to the spinal cord was altered significantly (Fig. 2). At 1 and 3 days post-crush the amount of labeled proteins accumulating in the cell bodies was reduced to $25 \%$ of normal $(p<0.001)$. At 5 days post-crush there was a significant increase in the accumulation which in amount approximated normal transport. This was followed by a rapid decline to $30 \%$ at 7 days. By 33 days. at which time normal motor function appeared to have been reestablished, the amount of retrograde accumulation was still significantly decreased $(p<0.001$ comparing 33 days to control or to 5 days postcrush).

In similarly treated animals the DRGs were examined with light microscopic autoradiography at 5 days post-crush 7 days post-injection. At this time point ( 12 days after the nerve crush) many of the neurons have irregular and eccentric nuclei as evidence of central chromatolysis, a finding seen only rarely in normal DRG or spinal cord. The silver grains were found almost exclusively over cell bodies ipsilateral to the injection, and were found over both neurons with eccentric nuclei as well as over some neurons which appeared normal by light microscopy (Fig. 3).

\section{DISCUSSION}

Strong circumstantial evidence implicates retrogradely transported biochemical signals in the cell body response to axonal injury (reviewed in $[6,14])$. Studies of retrograde transport using different methods to measure that transport have defined different changes following nerve injury. Bisby and Bulger demonstrated that reversal of anterograde transport at a nerve crush causing the premature return of anterogradely transported labeled proteins begins 1 hour after a crush [3]. This retrograde "turnaround" transport of radioactively labeled anterogradely transported proteins is maximal at 5 days and returns towards normal by 30 days [5]. On the other hand, although horseradish peroxidase (HRP) 


\section{DHG 7 DAY TRANSPORT}

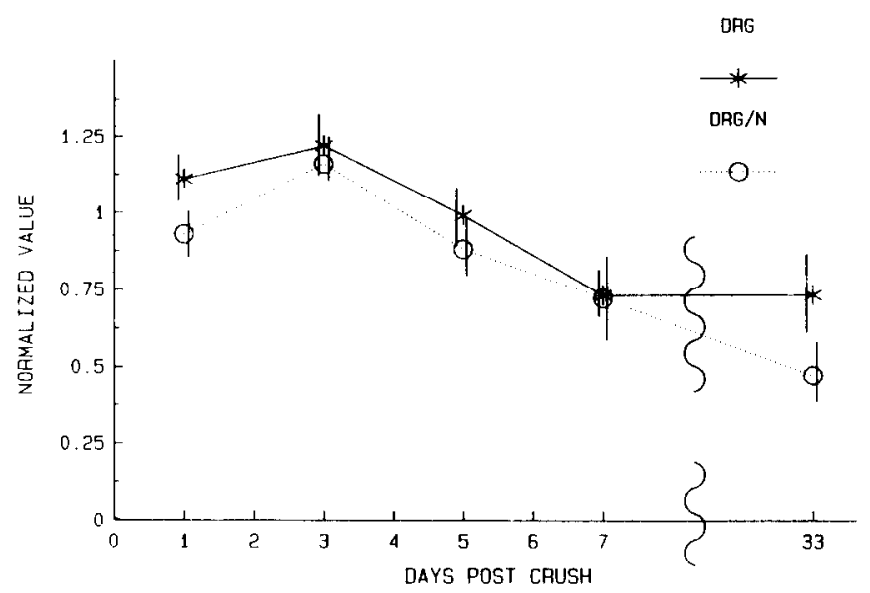

FIG. 1. Accumulation of radioactively labeled proteins in the DRG 7 days after labeling of axonal proteins with ${ }^{3} \mathrm{H}$ NSP. Data is presented both as DPM and as the DRG/nerve ratio, normalized against control animals. Mean $\pm \mathrm{SEM}, \mathrm{N}=6,7,5,6,6,6$ for control and 1, 3, $5,7,33$ days post crush respectively. The difference between the 5,7 and 33 days post crush values and either the 1 or the 3 day post crush values are statistically significant $(p<0.01)$.
SPINAL CORO 7 DAY TRANSPORT

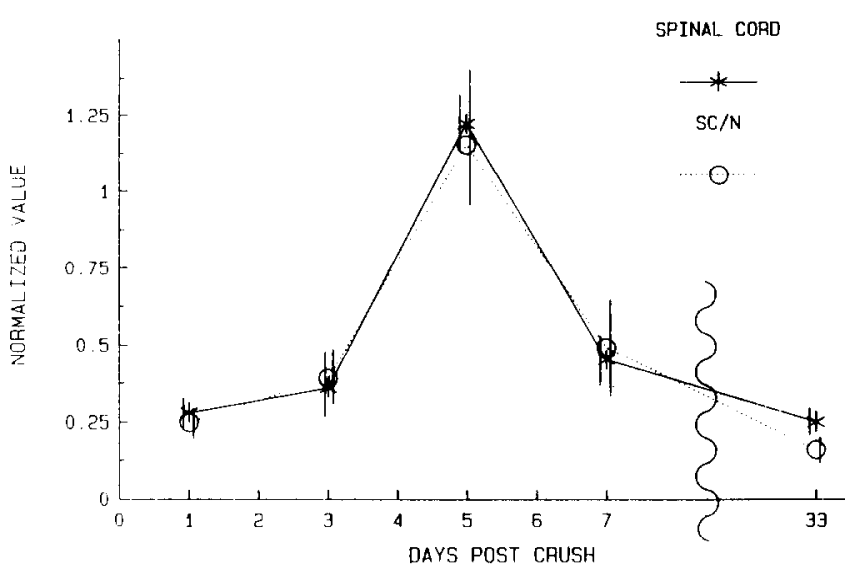

FIG. 2. Accumulation of radioactively labeled proteins in the ventral horn of lumbar spinal cord 7 days after labeling of axonal proteins with ${ }^{3} \mathrm{H}$ NSP. Data presentation and $\mathrm{N}$ for each group identical to Fig. 1. The difference between $1,3,7$ and 33 days post crush and control or 5 day post crush are statistically significant $(p<0.001)$.
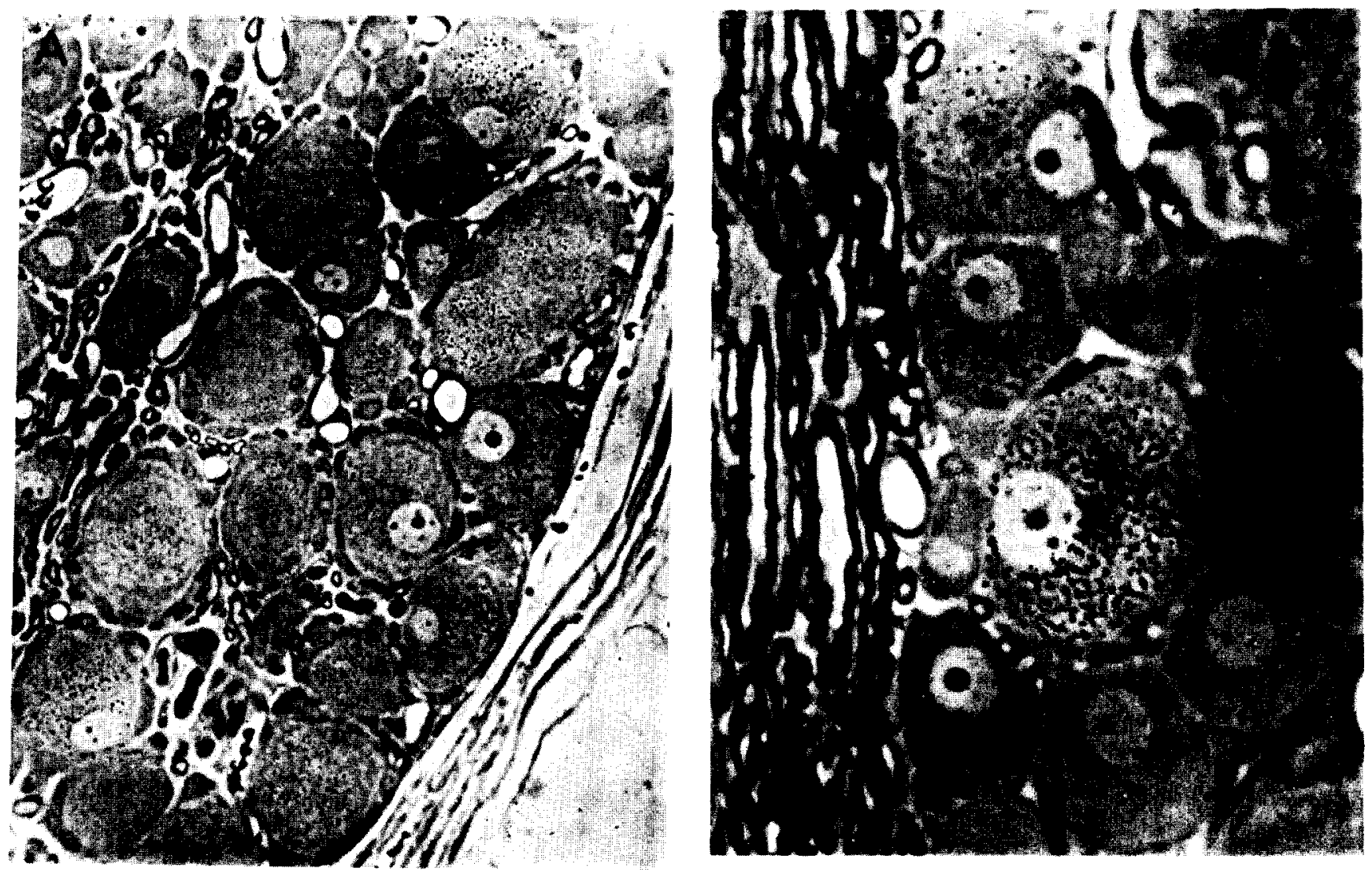

FIG. 3. Light microscopic autoradiograph of DRG from animal injected with ${ }^{3} \mathrm{H}$ NSP 5 days after crush, sacrificed 7 days after ${ }^{3} \mathrm{H}$ NSP injection. Silver grains are seen principally over neuronal perikarya, and are found both in normal appearing neurons and in neurons with eccentric nuclei characteristic of chromatolysis. A. $\times 375 ;$ B. $\times 720$. 
applied to the region of a nerve crush is taken up by the damaged axons and transported retrogradely to the cell bodies in the DRG $[15,16]$, the retrograde transport of intravenously injected HRP to the facial nucleus of the mouse is reduced from 1 hour to 5 days after facial nerve cut, and returns to levels greater than normal only at the time that reinnervation of the muscles of the vibrissae occurs [19]. No similar semi-quantitative studies of retrograde transport of exogenous macromolecules in the sciatic nerve have been reported.

The ${ }^{3} \mathrm{H}$ NSP technique obtains information complementary to that obtained by those other studies. The "turnaround" studies measure the retrograde transport of endogenous proteins which have recently been transported into the axon. ${ }^{3} \mathrm{H}$ NSP randomly labels intraaxonal proteins independent of their origin or time of synthesis, so that measurement of ${ }^{3} \mathrm{H}$ NSP accumulation does not discriminate between proteins which were synthesized in the neuronal perikaryon and those proteins which were synthesized outside the neuron and taken up by axon terminals. Further, in ligature studies accumulation of retrogradely transported proteins is measured in the axon $15 \mathrm{~mm}$ proximal to the crush injury, while using ${ }^{3} \mathrm{H}$ NSP labeling we measure accumulation at the cell body.

It is likely that the changes we observed represent a change in transport, and not an artifact of the crush injury. The changes were the same whether transport was expressed as total counts reaching the cell body or as the ratio of counts reaching the cell body to those remaining in nerve. There was no difference in total labeling of nerve between controls and crush animals. Furthermore, if the change were simply due to an artifact at the crush site, we would expect the changes to be similar in both sensory and motor nerves, but on the contrary those changes differed significantly. There is, though, one caveat which must be considered in interpreting these results. As we have discussed in detail previously [8], the amount of radioactively labeled proteins accumulating at the cell body at a time after ${ }^{3} \mathrm{H}$ NSP labeling of axonal protein reflects not only the amount of and rate of transport but also the degradation rate of these proteins within the cell bodies. Thus, reduced 7 day accumulation might represent increased degradation at the cell body, but that degradation rate cannot be directly measured.

How does the time course of the alterations in retrograde transport correspond to the neuronal response to injury? In rat sciatic nerve crushed sensory axons begin to regenerate, after a lag of 2 days, at a rate of $4 \mathrm{~mm} /$ day $[1,18]$. Chromatolysis begins 6 days after peripheral axotomy and is maximal at 11-19 days, while qualitative differences in rapidly transported proteins begin 7 days after a cut and are maximal at 18 days [24]. Similarly, anterograde axonal transport of substance P like immunoreactivity (presumably within sensory neurons) is reduced following a nerve crush but that reduction does not become statistically significant until 14 days after injury [4]. The most rapidly regenerating motor axons, like the sensory axons, also regenerate at 4 $\mathrm{mm} /$ day after a 2 day lag, but the majority appear to advance at $3 \mathrm{~mm} /$ day after a delay of 3 days [11]. Rapid anterograde transport of acetylcholinesterase in motor neurons is reduced 1-2 days after injury and reaches a minimum at 5-11 days after nerve crush $[11,21]$. Anterograde transport of specific growth associated proteins in motor neurons begins to increase within 1-3 days after sciatic nerve crush [2], and the ratio of transported neurofilaments to transported tubulin in those cells is reduced by $30.40 \%$ as early as 3 days after axonal injury [13].

The decreases in retrograde transport we have described occur too late to include the acute "signal" which triggers chromatolysis or initiates the synthesis and transport of growth associated proteins. One day accumulation, which would occur soon enough, was not significantly altered by nerve crush. The sudden rise in 7 day transport to the spinal cord 5 days after nerve crush corresponds to the time when the majority of axon terminals are growing through the crush region [11], and may reflect uptake of exogenous macromolecules by growth cones passing through the crush region. These proteins do not reach the cell body until 12 days after the crush, at which time the acute morphologic and biochemical cell body reactions are well advanced. The 7 day transport falls again by 5 days and remains depressed even at 33 days, by which time reinnervation appeared to be complete and motor function in the foot had returned to normal.

Why is 7 day transport reduced to a much greater degree in motor neurons than in sensory neurons? One possible explanation is that there may be different proportions of endogenous and exogenous macromolecules in retrograde transport in those two systems. Motor neurons, with active synaptic vesicle release and membrane recycling at their terminals, exhibit both receptor mediated endocytosis of specific macromolecules as well as non-specific pinocytosis of extracellular macromolecules. Much less is known about the dynamics of the peripheral process of sensory neurons. Although receptor mediated uptake and retrograde axonal transport of specific macromolecules such as nerve growth factor (NGF) has been demonstrated, the amount of nonspecific pinocytosis in these neurons may be less than in motor neurons with their active terminal vesicular release and recycling. The observation that 7 day transport to DRG neurons is less affected by crush than 7 day transport to spinal cord neurons suggests that the former may be comprised primarily of endogenous neuronal proteins, while the latter may contain a significant proportion of proteins which originated outside the neuron and were taken up at the terminal.

In summary, we have defined specific reductions in retrograde transport in motor and sensory neurons after an axonal crush injury. The time course is too slow to include the "signal" for chromatolysis, and suggests rather that substances involved in long term maintenance of the neuron may be transported with these proteins. These reductions are similar to those we have found in neuropathic conditions of intoxication with IDPN and in STZ induced diabetes $[9,10]$. The reduction in retrograde transport in those conditions may serve as a signal to the cell body of metabolic injury to the axon.

\section{ACKNOWLEDGEMENTS}

We wish to acknowledge the excellent technical assistance of Julie Staple in microscopy and autoradiography. This research was funded by VA Merit Review Grants to Dr. Mata and to Dr. Fink. A preliminary communication of the results was presented in abstract form at the Annual Meeting of the Society for Neuroscience in Washington, DC in November, 1986. 


\section{REFERENCES}

1. Berenberg, R. A., D. S. Forman, D. K. Wood, A. DeSilva and J. Demaree. Recovery of peripheral nerve function after axotomy-effect of triiodothyronine. Exp Neurol 57: 349-363, 1977.

2. Bisby, M. A. Changes in the composition of labeled protein transported in motor axons during regeneration. J Neurobiol 11: 435-445, 1980.

3. Bisby, M. A. and V. T. Bulger. Reversal of axonal transport at a nerve crush. $J$ Neurochem 29: 313-320, 1977.

4. Bisby, M. A. and P. Keen. Axonal transport of substance P-like immunoreactivity in regenerating rat sciatic nerve. Brain Res 361: 396-399, 1985.

5. Bulger, V. T. and M. A. Bisby. Reversal of axonal transport in regenerating nerves. $J$ Neurochem 31: 1411-1418, 1978.

6. Cragg, B. G. What is the signal for chromatolysis? Brain Res 23: $1-21,1971$

7. Fink, D. J., D. Purkiss and M. Mata. Rapid retrograde transport of proteins in sensory neurons. Brain Res 345: 394-397, 1985.

8. Fink, D. J., D. Purkiss and M. Mata. A quantitative study of retrograde axonal transport in motor and sensory neurons. Brain Res Bull 16: 537-540, 1986.

9. Fink, D. J., D. Purkiss and M. Mata. IDPN blocks retrograde axonal transport. J Neurochem 47: 1032-1038, 1986.

10. Fink, D. J., D. Purkiss and M. Mata. Alterations in retrograde axonal transport in streptozotocin diabetic rats. Diabetes, in press.

11. Forman, D. S. and R. A. Berenberg. Regeneration of motor axons in the rat sciatic nerve studied by labeling with axonally transported radioactive proteins. Brain Res 156: 213-225, 1979.

12. Heiwall, P. O., A. Dahlstrom, P. A. Larsson and S. Booj. The intraaxonal transport of acetylcholine and cholinergic enzymes in rat sciatic nerve during regeneration after various types of axonal trauma. J Neurobiol 10: 119-136, 1979.

13. Hoffman, P. N., G. W. Thompson, J. W. Griffin and D. L. Price. Changes in neurofilament transport coincide temporally with alterations in the caliber of axons in regenerating motor fibers. J Cell Biol 101: 1332-1340, 1985.
14. Kieman, J. A. An explanation of axonal regeneration in peripheral nerves and its failure in the central nervous system. Med Hypoth 4: 15-26, 1978.

15. Kristensson, K. and $Y$. Olsson. Retrograde transport of horseradish peroxidase in transected axons. II. Relations between rate of transfer from the site of injury to the perikaryon and the onset of chromatolysis. J Neurocytol 4: 653-661, 1975.

16. Kristensson, K., Y. Olsson and J. Sjostrand. Axonal uptake and retrograde transport of exogenous proteins in the hypoglossal nerve. Brain Res 32: 399-408, 1971.

17. Miller, R. G. Simultaneous Statistical Inference. New York: McGraw Hill, 1966, p. 15.

18. McQuarrie, I. G., B. Grafstein and M. B. Gershon. Axonal regeneration in the rat sciatic nerve: effect of a conditioning lesion and of dbc-AMP. Brain Res 132: 443-453, 1977.

19. Olsson, T. P. and K. Kristensson. Uptake and retrograde axonal transport of horseradish peroxidase in regenerating facial motor neurons of the mouse. $J$ Neuracytol 7: 323-336, 1978.

20. Pilar, G. and L. J. Landmesser. Axotomy mimicked by localized colchicine application. Science 177: 1116-1118, 1972.

21. Schmidt, R. E. and D. B. McDougal. Axonal transport of selected particle-specific enzymes in rat sciatic nerve and its response to injury. J Neurochem 30: 527-536, 1978.

22. Singer, P. A., S. Mehler and H. L. Fernandez. Blockade of retrograde axonal transport delays the onset of metabolic and morphologic changes induced by axotomy. J Neurosci 2: 1299 1306, 1982.

23. Sparrow, J. R. and J. A. Kiernan. Uptake and retrograde transport in regenerating axons. Acta Neuropathol (Berl) 47: 39-47, 1979.

24. Theiler, R. F. and W. O. McClure. Rapid axoplasmic transport of proteins in regenerating sensory nerve fibers. $J$ Neurochem 31: 433-447, 1978 . 